\title{
Powder and Solvent for Solution for Infusion Dosage Form
}

National Cancer Institute

\section{Source}

National Cancer Institute. Powder and Solvent for Solution for Infusion Dosage Form.

NCl Thesaurus. Code C149795.

Sterile powder and sterile solvent intended for the preparation of a solution for infusion by dissolving the powder in the solvent. 